\title{
FINITE ELEMENT ANALYSIS OF COMPOSITE CONCRETE SLAB WITH PROFILED STEEL DECKING FOR DIFFERENT SHEAR SPANS
}

\author{
Suraj Vilas Bhise \\ Student, M. Tech Structural Engineering, \\ Applied Mechanics Department, \\ Government College of Engineering, Karad, \\ Maharashtra, India
}

\begin{abstract}
Composite roof slabs are demanding due to fast, light and economical construction work. Composite slabs consist of roof profile sheets formed in cold and concrete (light or moderate). This study studies the results of analysis and modeling of the $\mathrm{FE}$ of composite slabs to predict the stress-strain behavior, performance resistance and load deflection behavior. The investigation of the bending behavior of composite slabs is very complex. In this study, finite element analysis was performed using ANSYS 16.0, and the bending behavior of composite slabs was investigated. In this study, Is considered as a composite slab that can be examined briefly. Other parameters change, sheet thickness and cutting span. Cold forming cover profile the blades, that is, several cutting sections with intermediate reinforcements and without intermediate reinforcements, are considered three thicknesses $(0.8 \mathrm{~mm}, 1.0 \mathrm{~mm}$ and $1.2 \mathrm{~mm})$ for simulation purposes. In the present study, a model simulation of a static mesh load of $25 \mathrm{~mm}$ was considered. Flexural strength is also called transverse strength or flexural strength.
\end{abstract}

Keywords - Slab, Finite Element Analysis, ANSYS Workbench, Yield capacity, Stress-Strain behaviour, Deflection.

\section{INTRODUCTION}

Cold formed steel is widely used in composite floor decks and is permanently maintained as an integral part of the floor system. They perform two functions. It serves as a concrete formwork and concrete slabs and acts as a tensile reinforcement. The only additional steel that must be provided is to manage the shrinkage and temperature. For continuous slabs, the reinforcing steel must withstand the negative bending moments in the supports. This type of flooring results in faster construction, lighter floors and reasonable use of building materials. They also offer other benefits, such as easy handling, good roof surfaces and conduits suitable for routing services of public services. Finally, the thin sheet is very light and can be conveniently transported, easy to handle and

\author{
U. L. Deshpande \\ Professor, \\ Applied Mechanics Department, \\ Government College of Engineering, Karad, \\ Maharashtra, India
}

placed by construction personnel. Some of the disadvantages observed for the system are the need to protect against inadequate fire resistance, the need for proper coupling between the steel platform and the concrete, and the damage of high local loads. Even if the steel platform is galvanized, it is recommended to apply anticorrosive paint to the exposed surface. Molding effects and edge deformation must also be handled during design. The term 'composite steel deck slab' means that there are regulations in systems that combine concrete slab with steel deck by some mechanical means. In other words, a mechanical lock is required for a combination of steel and concrete platform. Basically, this is provided by various 'shear transfer devices', such as shear studs, embossing, cable routing, holes, etc. An example of a composite steel deck floor slab system is shown in Figure1.

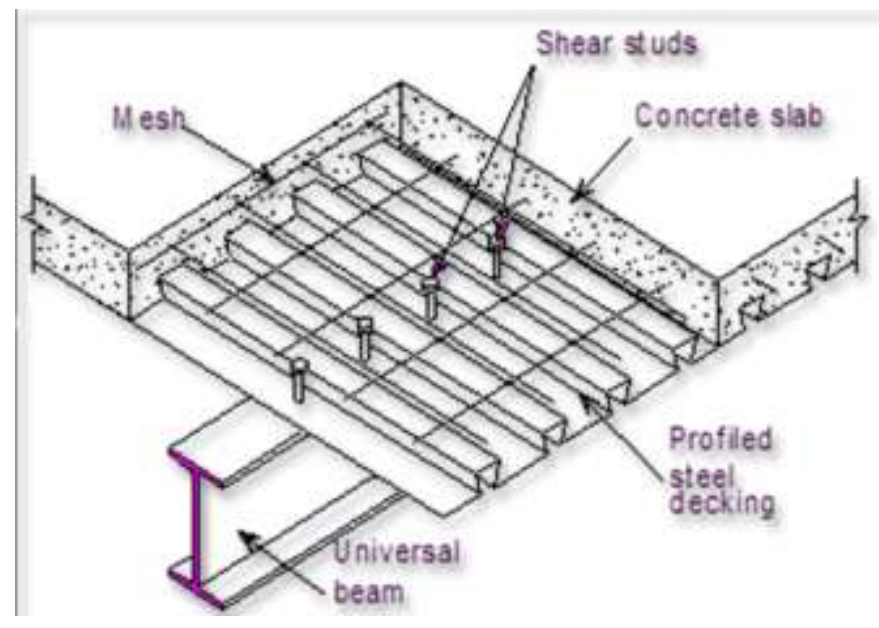

Fig. 1. Composite steel deck floor slab

\section{METHODOLOGY}

\section{A. Structural Modelling -}

The finite element model of the slab is made of concrete and steel profile platforms with non-linear material properties. 
Nonlinear 3D FE modelling and slab element analysis is performed using ANSYS 16.0. The dimensions of the structure are $820 \times 3000 \mathrm{~mm}$, the effective depth is $77.5 \mathrm{~mm}$ and the height is $105 \mathrm{~mm}$. The profile sheets of the cold forming platform are $55 \mathrm{~mm}$ high and $0.8 \mathrm{~mm}, 1.0 \mathrm{~mm}$ and $1.2 \mathrm{~mm}$ thick respectively. In ANSYS 16.0, the properties of steel and concrete materials can be characterized by uniform materials. The boundary condition is articulated at one end $(\mathrm{U} 1=\mathrm{U} 2=\mathrm{U} 3=0)$ and the other end has a roller $(\mathrm{U} 1=\mathrm{U} 2=$ $0)$. These two parts consist of a linear hexahedral element and eight noded elements with a mesh size of $25 \mathrm{~mm}$. The specimens were divided into 10 shear span sizes of 3 sets of specimens, 5 sets were analyzed to detect shorter shear span loads and another 5 sets were analyzed to determine the longest shear span loads. Shear spans of $300 \mathrm{~mm}, 400 \mathrm{~mm}$, $450 \mathrm{~mm}, 500 \mathrm{~mm}$ and $600 \mathrm{~mm}$ were selected for short-span interval loads, but $750 \mathrm{~mm}, 850 \mathrm{~mm}, 900 \mathrm{~mm}, 1000 \mathrm{~mm}$ and $1200 \mathrm{~mm}$ were selected for long span loads. For each set of samples of three different thicknesses, each sample was tested up to yielding in a four-point load test.

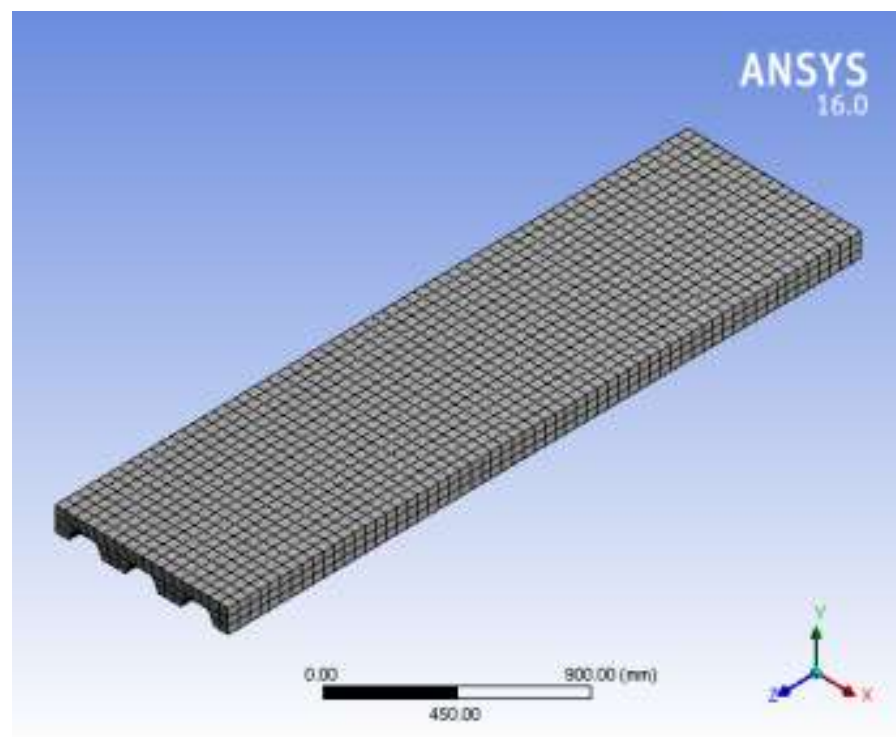

Fig. 2. FE Modelling and Meshing

\section{B. Load, Boundary condition and Numerical control -}

The end of the slab is provided with a roller support and a hinge support. The edge of the steel platform along the length of the slab and the node on the concrete side side of the central section receive the appropriate boundary conditions to simulate the lateral continuity of the slab. This greatly reduces the size of the model and the calculation time. The load is applied at a specific distance from the end supports to two line loads with a value of $121.95 \mathrm{~N} / \mathrm{mm}$. Therefore, the result will be two point loads of magnitude $100 \mathrm{kN}$ that will be applied to the higher fiber nodes of the concrete (Figure 3). The tolerance associated with this convergence criterion (ANSYS CNVTOL command) and the increments of the loading steps are varied to solve possible numerical problems. The Newton-Raphson method is used as the incremental-iterative solution process.

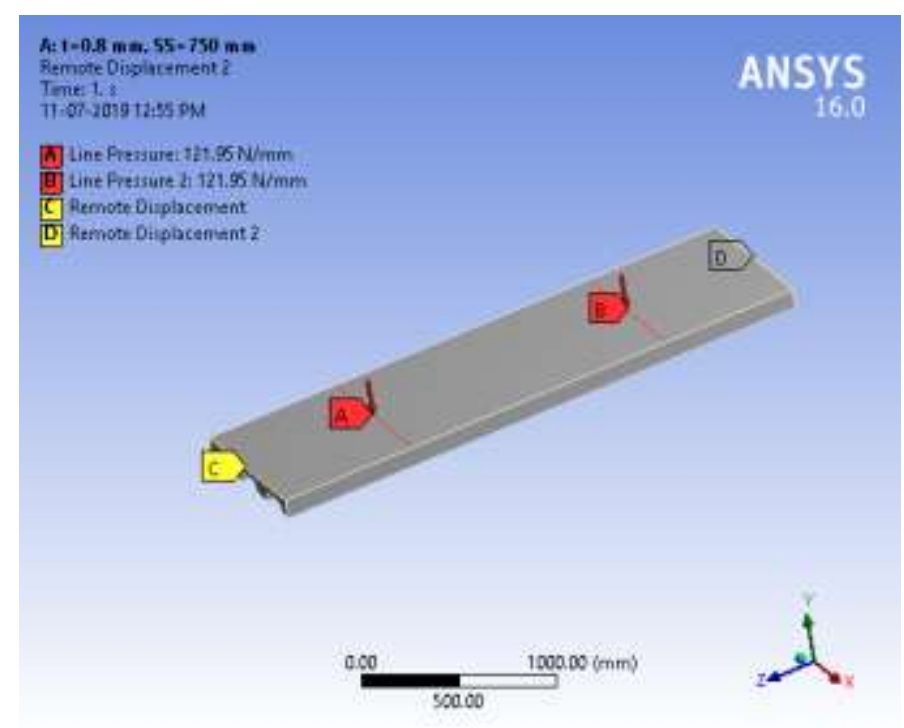

Fig. 3. Loads and boundary conditions

\section{Material Specifications -}

Table - 1 Concrete properties used in the FE model

\begin{tabular}{|c|c|}
\hline Concrete_Properties & Value \\
\hline Density & $2400 \mathrm{~kg} / \mathrm{m}^{3}$ \\
\hline Young's modulus & $5000 \sqrt{ } c k$ \\
\hline Yield strength & $25 \mathrm{~N} / \mathrm{mm}^{2}$ \\
\hline Poisson's ratio & 0.18 \\
\hline
\end{tabular}

Table - 2 Steel properties used in the FE model

\begin{tabular}{|c|c|}
\hline Steel Properties & Value \\
\hline Density & $7800 \mathrm{~kg} / \mathrm{m}^{3}$ \\
\hline Young's modulus & $2 \times 10^{5} \mathrm{~N} / \mathrm{mm}^{2}$ \\
\hline Yield strength & $250 \mathrm{~N} / \mathrm{mm}^{2}$ \\
\hline Poisson's ratio & 0.3 \\
\hline
\end{tabular}

\section{Preparation of the composite slab model -}

Two loading plans have been selected, one for short shear spans and the other for long shear intervals to form the two ends of the shear span section. Five series of shear spacing shorter than $300 \mathrm{~mm}, 400 \mathrm{~mm}, 450 \mathrm{~mm}, 500 \mathrm{~mm}$ and $600 \mathrm{~mm}$ have been selected. The criterion for the longest shear section is that the shear section should be as long as possible and should provide failure in the longitudinal section. Therefore, the longer the shear span, the more the values of $750 \mathrm{~mm}, 850$ 
$\mathrm{mm}, 900 \mathrm{~mm}, 1000 \mathrm{~mm}$ and $1200 \mathrm{~mm}$ were selected. For comparison, the thickness of steel platform slabs such as 0.8 $\mathrm{mm}, 1.0 \mathrm{~mm}$ and $1.2 \mathrm{~mm}$ are different.

\section{ANALYTICAL CALCULATIONS}

The expression used here to calculate the maximum deflection of a slab in a flexural analysis. Simply deflection of the supported section.

$$
\Delta \max =\frac{F \times a\left(3 L^{2}-4 a^{2}\right)}{24 E I}
$$

Where, $\mathrm{F}$ is load applied, $\mathrm{L}$ is total span, a is shear span, $\mathrm{E}$ is combined modulus of elasticity and I is moment of inertia of composite section.

The elastic stiffness calculations are based on the steel that has been transformed into a concrete member equivalent to a simple supported boundary condition. In the case of stiffness calculations, the average value of the moment of inertia is cracked and the values not cracked. The moment of inertia cracked and not fractured is calculated using the following equation, which is an amendment to the ASCE standard equation (Specification 1984).

Moment of Inertia for Cracked section :

$$
\left.I_{C r}=\frac{b}{3}\left(y_{C C}\right)^{3}+n A_{S}\left(y_{C S}\right)^{2}+n I_{s f}\right)
$$

Moment of Inertia for uncracked section :

$$
\begin{aligned}
I_{u n}= & \frac{b h_{C}^{3}}{12}+b h_{C}\left(y_{c c}-0.5 h_{C}\right)^{2}+n I_{s f}+n A_{5} y_{c s}^{2} \\
& +\frac{W_{r} b d_{d}}{C_{5}}\left[\frac{d_{d}^{2}}{12}+\left(h-y_{c C}-0.5 d_{d}\right)^{2}\right]
\end{aligned}
$$

\section{RESULTS AND DISCUSSIONS}

The following is a simulation of 30 models in ANSYS 16.0. The results are divided into 6 groups according to the cold-formed roof profile sheets $0.8 \mathrm{~mm}$ thick with and without intermediate reinforcements and $1.2 \mathrm{~mm}$ thick with or without intermediate reinforcements according to different cutting intervals $(850 \mathrm{~mm}, 950 \mathrm{~mm}, 350 \mathrm{~mm}$ and $380 \mathrm{~mm})$. The deflection and deformation deformation patterns for one of the models are shown in Figures 6 and 7, respectively. Obtain a variation pattern for the rest of the model in a similar way.

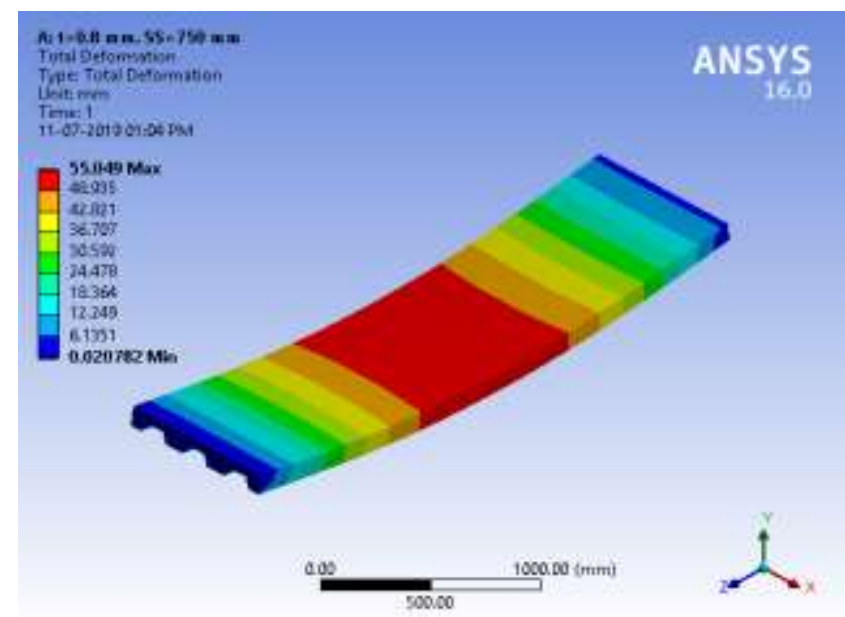

Fig. 4. Deformation of composite slab

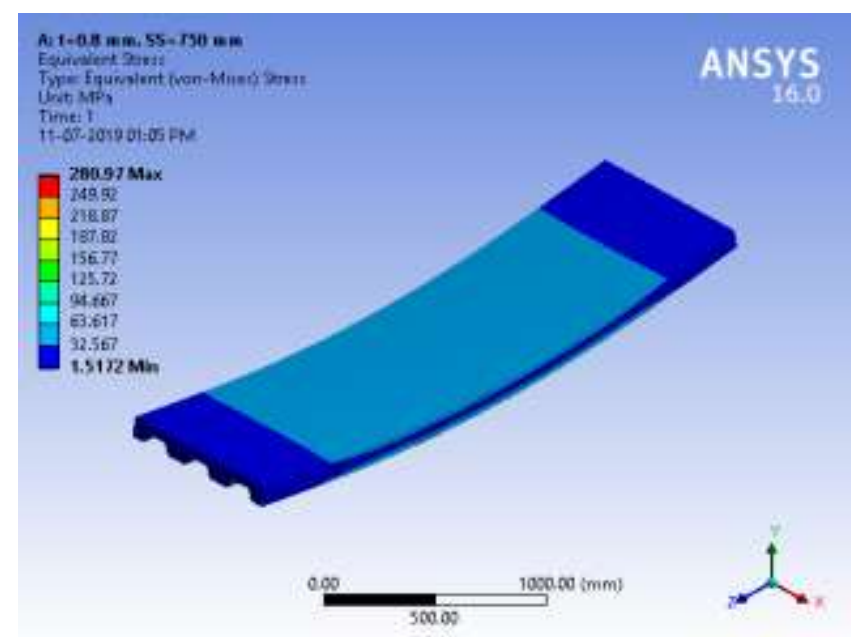

Fig. 5. Equivalent Stress in Composite Slab

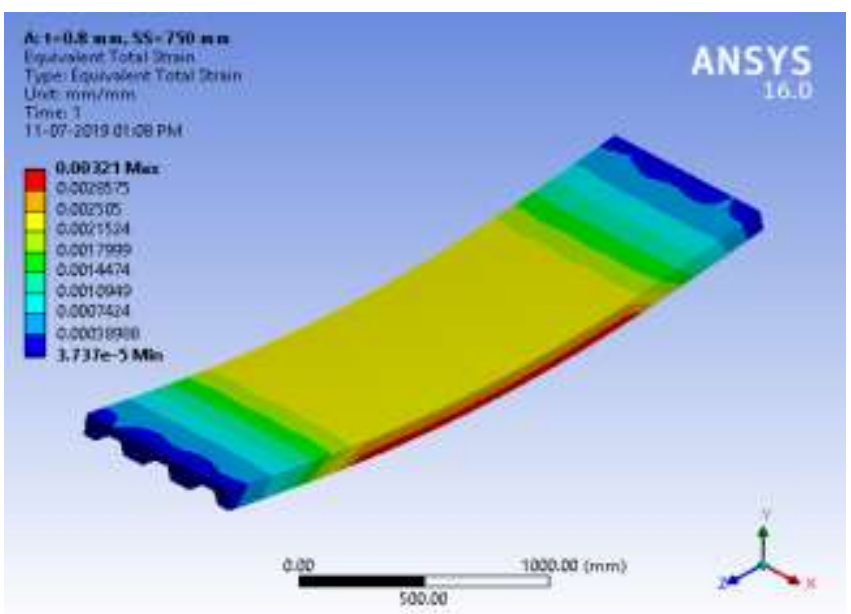

Fig. 6. Equivalent Strain in Composite Slab

From the stress and strain values obtained from the analysis, the typical Stress-Strain plots are drawn in ANSYS software 
results. Each shear span gives different values of maximum von-mises equivalent stress and maximum total strain values. Slabs with long shear spans show yield at low loads and short shear span slabs show yielding at greater values. But the modulus of elasticity for the model remains constant. Some of the Stress-Strain graphs are shown below:

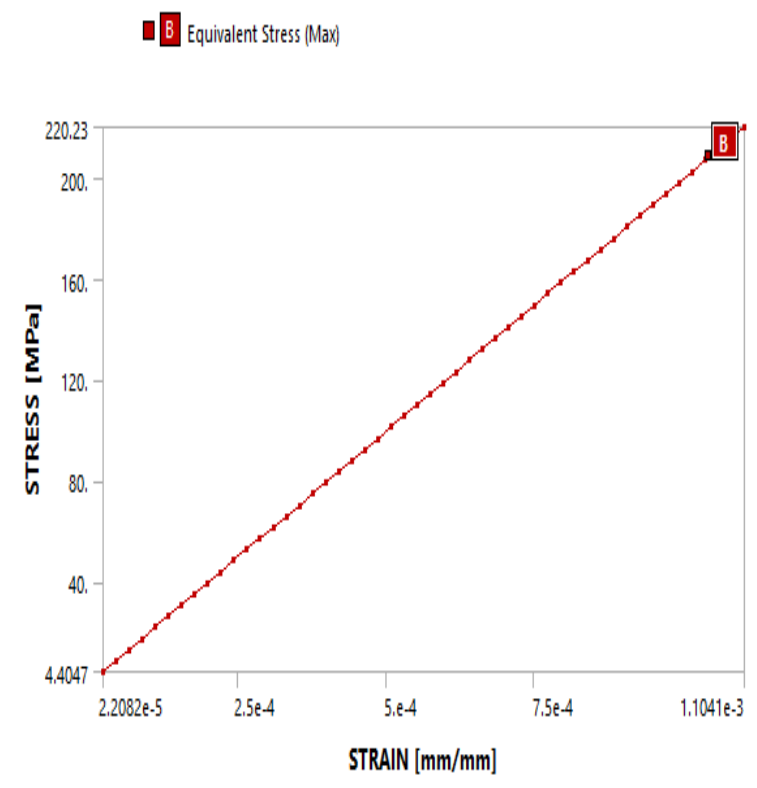

Chart 1. Stress-Strain for Shear span $=300 \mathrm{~mm}$

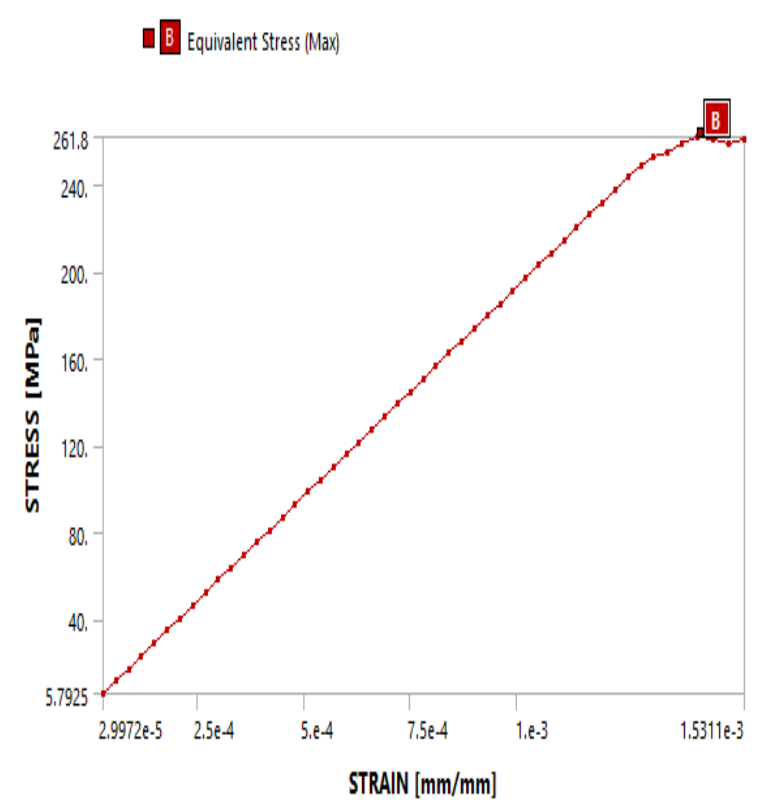

Chart 2. Stress-Strain for Shear $\mathrm{span}=400 \mathrm{~mm}$

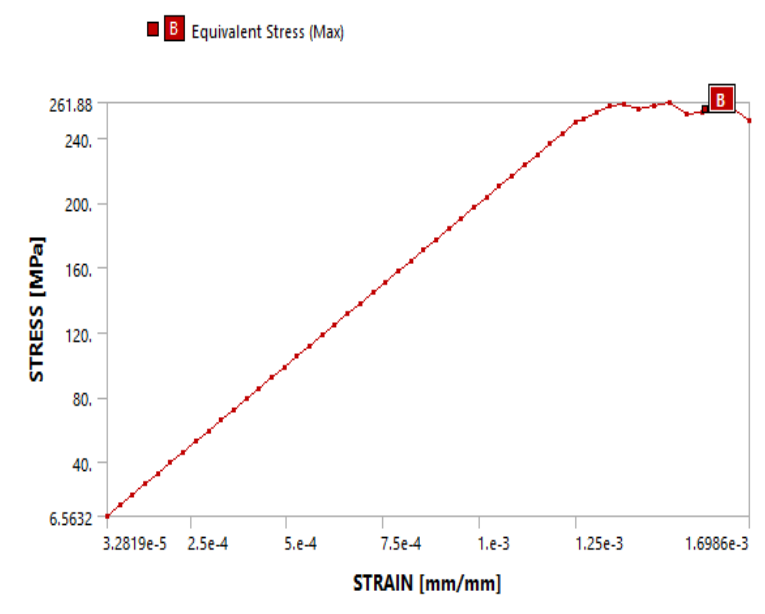

Chart 3. Stress-Strain for Shear span $=450 \mathrm{~mm}$

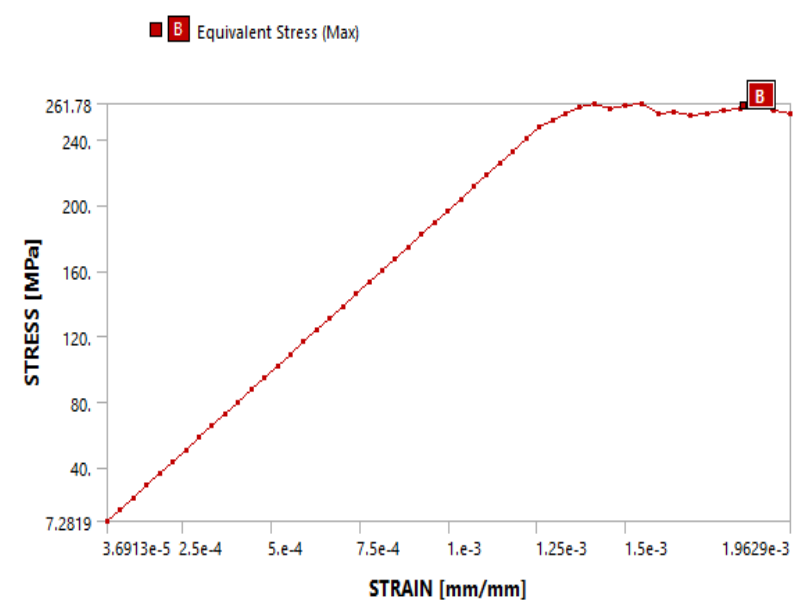

Chart 4. Stress-Strain for Shear $\operatorname{span}=500 \mathrm{~mm}$

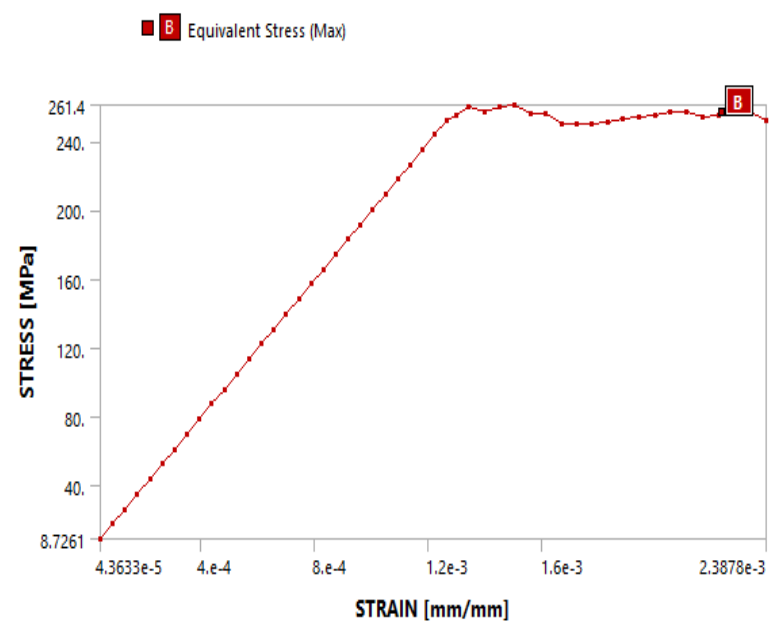

Chart 5. Stress-Strain for Shear span $=600 \mathrm{~mm}$ 
口 E Equivalent Stress (Max)

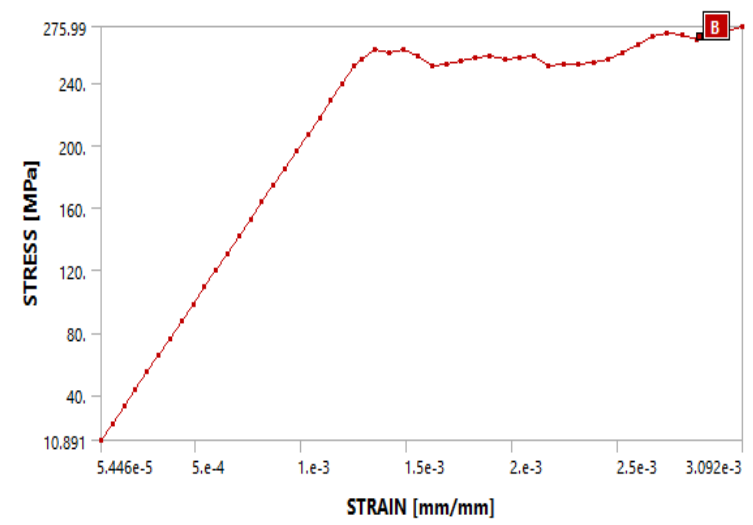

Chart 6. Stress-Strain for Shear $\mathrm{span}=750 \mathrm{~mm}$

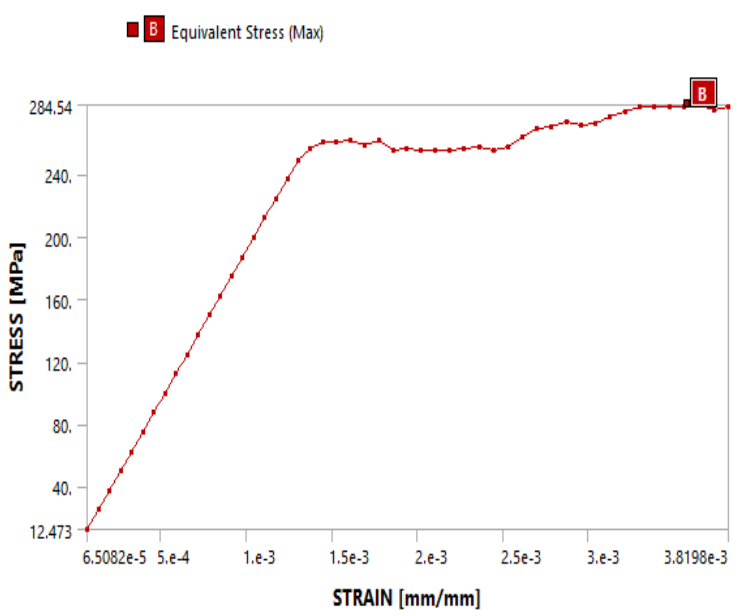

Chart 7: Stress-Strain for Shear span $=850 \mathrm{~mm}$

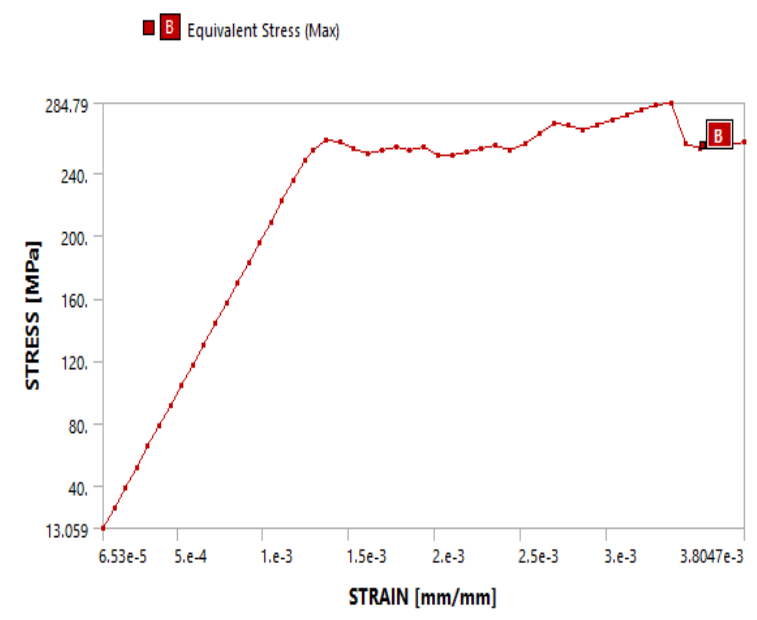

Chart 8. Stress-Strain for Shear span $=900 \mathrm{~mm}$

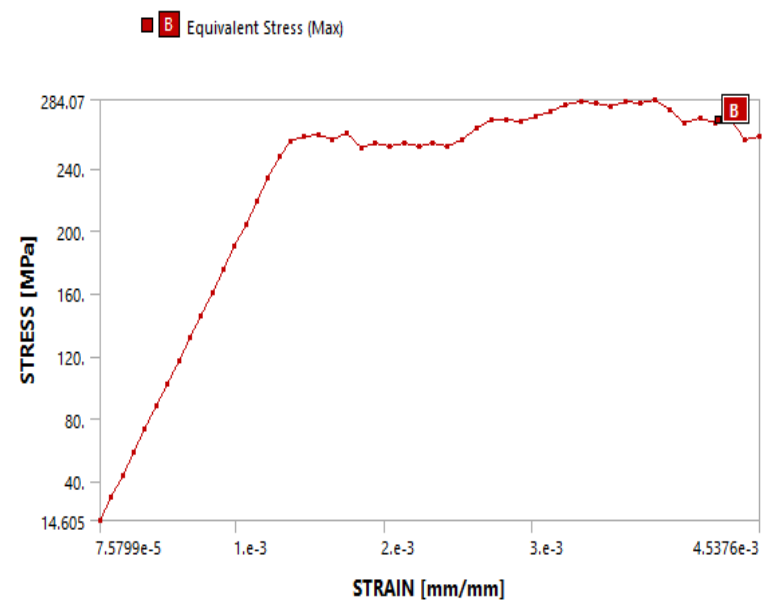

Chart 9. Stress-Strain for Shear span $=1000 \mathrm{~mm}$

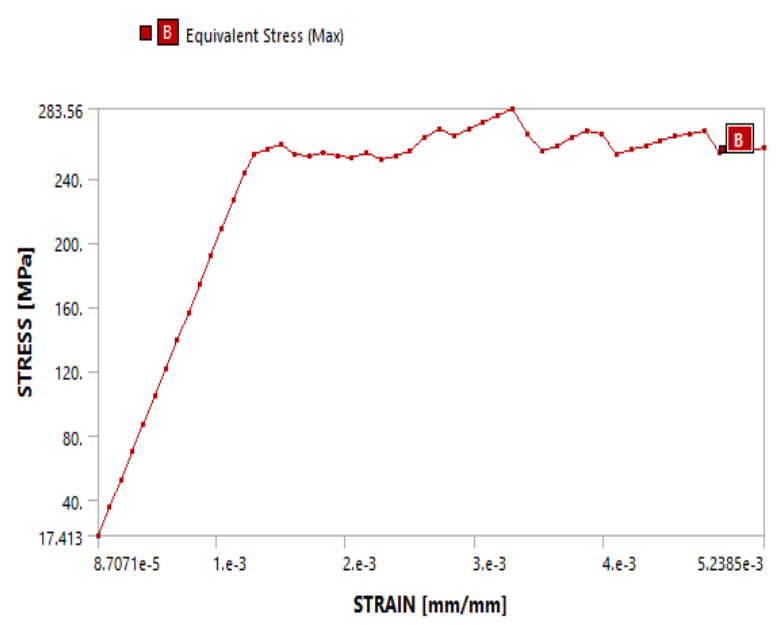

Chart 10. Stress-Strain for Shear span $=1200 \mathrm{~mm}$

The results of the $0.8 \mathrm{~mm}$ steel cover thickness are shown above for 10 different values of shear spans. Five series of shorter cutting intervals of $300 \mathrm{~mm}, 400 \mathrm{~mm}, 450 \mathrm{~mm}, 500$ $\mathrm{mm}$ and $600 \mathrm{~mm}$ were chosen and for longer shear spans, values of $750 \mathrm{~mm}, 850 \mathrm{~mm}, 900 \mathrm{~mm}, 1000 \mathrm{~mm}$ and $1200 \mathrm{~mm}$ were chosen.

Results obtained from the simulation of 30 models in ANSYS Workbench 16.0. The stress-strain curves are plotted with different shear spans shows that the tables with the highest shear spans produce first, and more time and larger load values are required for the shorter cutting periods to produce and reach their limits deformation. 
International Journal of Engineering Applied Sciences and Technology, 2019

Vol. 4, Issue 3, ISSN No. 2455-2143, Pages 342-348

Published Online July 2019 in IJEAST (http://www.ijeast.com)

Table -3 Yield Capacity of Composite slab specimens

\begin{tabular}{|c|c|c|c|c|c|}
\hline $\begin{array}{c}\text { Steel deck } \\
\text { thickness (mm) }\end{array}$ & $\begin{array}{c}\text { Shear Span } \\
(\mathbf{m m})\end{array}$ & Yield Load (kN) & Deflection (mm) & $\begin{array}{c}\text { Equivalent Stress } \\
\left(\mathbf{N} / \mathbf{m m}^{2}\right)\end{array}$ & Equivalent Strain \\
\hline 0.8 & 750 & 88 & 22.123 & 250.94 & $1.25 E-03$ \\
\hline 0.8 & 900 & 72 & 20.854 & 246.73 & $1.23 E-03$ \\
\hline 0.8 & 1200 & 56 & 19.342 & 252 & $1.27 \mathrm{E}-03$ \\
\hline 1.0 & 750 & 92 & 22.207 & 250.5 & $1.25 \mathrm{E}-03$ \\
\hline 1.0 & 900 & 76 & 21.136 & 248.12 & $1.24 \mathrm{E}-03$ \\
\hline 1.0 & 1200 & 60 & 18.570 & 255 & $1.29 \mathrm{E}-03$ \\
\hline 1.2 & 750 & 96 & 22.300 & 249.06 & $1.25 \mathrm{E}-03$ \\
\hline 1.2 & 900 & 80 & 21.413 & 248.87 & $1.24 \mathrm{E}-03$ \\
\hline 1.2 & 1200 & 64 & 19.150 & 248.89 & $1.24 \mathrm{E}-03$ \\
\hline
\end{tabular}

\section{Maximum Deflections (mm)}

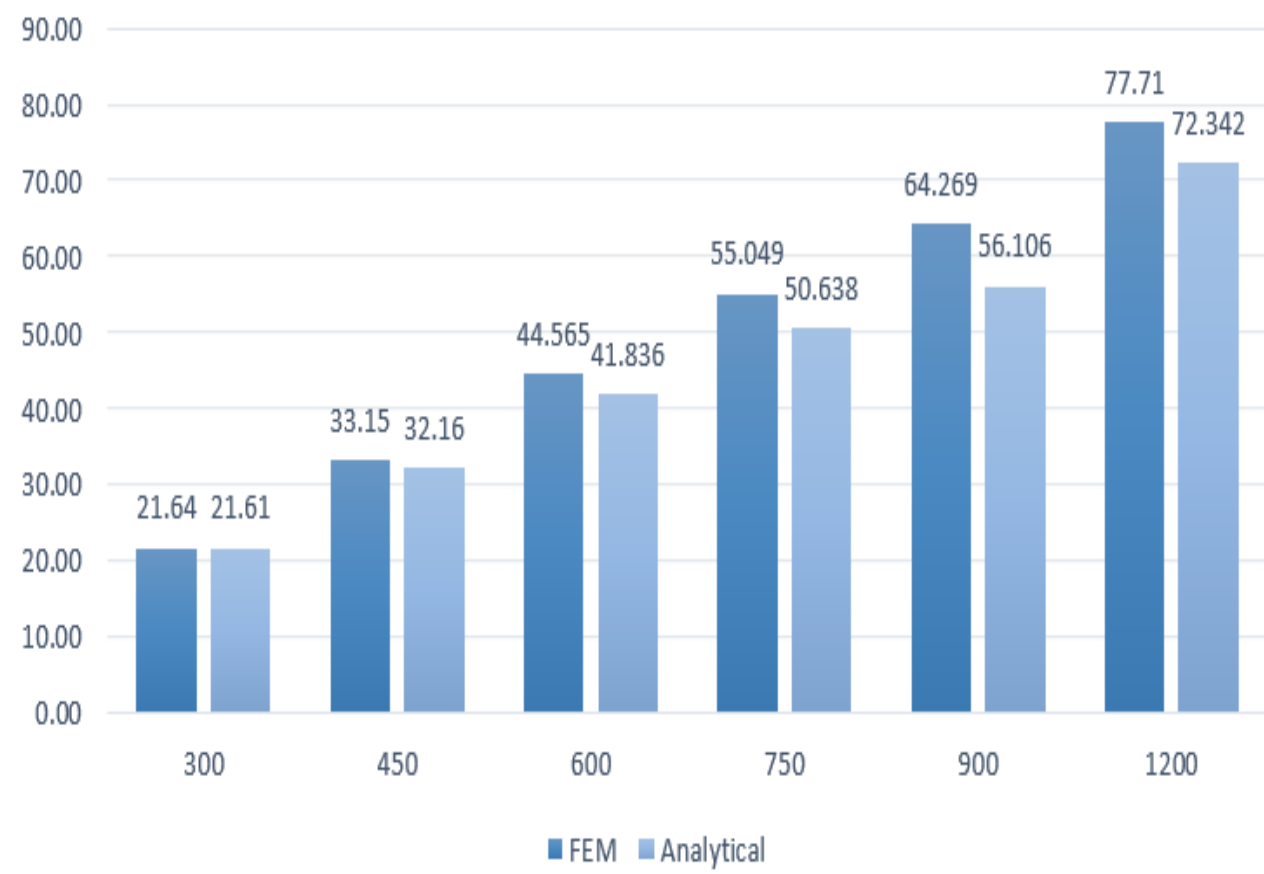

Chart 11. Maximum deflection comparison FEM and Analytical values 


\section{International Journal of Engineering Applied Sciences and Technology, 2019 \\ Vol. 4, Issue 3, ISSN No. 2455-2143, Pages 342-348 \\ Published Online July 2019 in IJEAST (http://www.ijeast.com)}

\section{CONCLUSION}

A simulative approach to determine the performance resistance of composite slabs has been presented. The approach is based on the analysis of finite elements with the help of ANSYS Workbench 16.0. The results of 30 different samples are verified with FE analysis. It is observed that the cutting time affects the resistance of the slab sample. For large sections of cut, only the flexural strength decides the fault while the short sections fail in the cut.

A comparison between analytical and simulation studies shows that we can use computer-assisted results as an option for experimental tests.

- Simulation results of composite slabs for $0.8 \mathrm{~mm}$ thickness show that the maximum deflection values by ANSYS and analytical calculations vary by $1-10 \%$ on the higher side for both long and short shear spans.

- Results of composite slabs for maximum deflections decreases by 3-5\% with an increase in the thickness of the steel deck for short as well as long shear spans.

- Yield capacity of composite slab increases with increase in the thickness of deck sheet by about $5 \%$ whereas it decreases with an increase in shear span.

\section{Acknowledgement}

I take this opportunity to express my deep sense of gratitude towards my guide U. L. Deshpande, Professor, Applied Mechanics Department, Government College of Engineering, Karad and my co-guide Dr. M. R. Shiyekar, Professor, Applied Mechanics Department, Government College of Engineering, Karad.

I extent my sincere thanks to Dr. A. T. Pise, Principal, Government College of Engineering, Karad and Dr. Y. M. Ghugal, Head, Applied Mechanics Department, Government College of Engineering, Karad for providing institutional facilities and extending all kinds of cooperation. I am thankful to all the faculty members of Applied Mechanics, Civil Engineering Department and Library whose guidance and help have been immensely useful in my work.

\section{REFERENCE}

[1] Baskar R., et al.(2012) "Experimental and Numerical studies on Composite Deck Slabs." International Journal of Engineering and Technology. Vol: 2, No: 7, PP: 11161125.

[2] D. Datta et al. (2005) "Steel and Concrete Composite Construction -New Trend in India." IOSR Journal of Mechanical and Civil Engineering Vol: 3, No: 16, PP: 815.

[3] D. R. Panchal, et al. (July 2014) "Advanced Design of Composite Steel-Concrete Structural element in VB.NET." International Journal of Engineering Research and Applications Vol: 4, No:7, PP: 124-1387.
[4] EN 1994-1-1: Euro-code 4., et al. (2004) "Design of Composite Steel and Concrete Structures"- General rules and rules for Buildings. Brussels.

[5] Japan U. Shah, Prof. Merool D. Vikil, et al. (2014) "Parametric study of Composite Slab using Finite Element Analysis", International Journal of Futuristic Trends in Engineering and Technology. Vol: 1, No: 3, PP: 133-136.

[6] Kamal B, Alamelu G, Abinaya D, et al. (May-2016) “ Design of Composite Deck Slab" International Research Journal of Engineering and Technology. Vol: 03, No: 05, PP: 100-103.

[7] Marimuthu V, Seetharaman S., et al. (2007) "Experimental studies on composite deck slabs to determine the shear-bond characteristic $(\mathrm{m}-\mathrm{k})$ values of the embossed profiled sheet". Journal of Constructional Steel Research. Vol:63, PP: 791-803.

[8] Namdeo Hedaoo, Namdeo Raut, Laxmikant Gupta, et al. (Oct. 2015) "Composite Concrete Slabs with Profiled Steel Decking: Comparison Between Experimental and Simulation Study." American Journal of Civil Engineering. Vol: 3, No: 5, PP: 157-169.

[9] R. P. Johnson, et al. (2013) "Composite structures of Steel and Concrete" Third Edition Wiley Blackwell Publication, Wiley India Pvt. Ltd.

[10] R. P. Johnson, A. J. Shepherd, et al. (2013) "Resistance to longitudinal shear of composite slabs with longitudinal reinforcement", Journal of Construction Steel Research. Vol: 82, PP: 190-194.

[11] R.Sangeethal, P.S.Naufal Rizwan, S.Jansi Sheela, M.Franchis David, S.Daniel Raj, et al. (2018) "State of Art on Composite Slab Construction" International Journal of Applied Environmental Sciences. Vol: 13, No: 1 PP: 1-8.

[12] S. Chen, et al. (2003) "Load carrying Capacity of Composite Slabs", Journal of Construction Steel Research. Vol: 59, PP: 385-403.

[13] Specifications for the design and construction of composite slabs, (1984). ASCE, New York.5.

[14] W. Samuel Easterling, Craig S. Young, Associate Members ASCE, et al. (1992) "Strength of Composite Slabs", Journal of Structural Engineering, Vol: 118 No: 9, PP: 2370-2389. 